\title{
Atividade antioxidante in vitro de Lippia origanoides H.B.K
}

\author{
In vitro antioxidant activity of Lippia origanoides H.B.K \\ Actividad antioxidante in vitro de Lippia origanoides H.B.K
}

\section{Resumo}

O estresse oxidativo constitui-se em uma ameaça constante para o organismo. Em virtude disto, uma série de defesas antioxidantes, além de sistemas de reparo em células evoluíram com o objetivo de proteção contra a destruição e danos ocasionados pelos radicais livres. As plantas produzem uma enorme variedade de antioxidantes que tendem a agir contra o dano celular por meio da remoção de espécies reativas de oxigênio e espécies reativas de nitrogênio. A Lippia origanoides Humboldt, Bonpland e Kunth, família Verbenaceae, é um arbusto aromático conhecido como "Alecrim-do-campo", sendo responsável por variadas atividades farmacológicas e biológicas, inclusive a proteção antioxidante. Este trabalho teve como objetivo analisar a composição química do óleo essencial de L.origanoides HBK (OELO) e avaliar sua atividade antioxidante in vitro. Para tanto foi avaliado o potencial antioxidante in vitro pelos métodos potencial redutor, 2,2difenil-1-picrilhidrazila (DPPH), inibição da peroxidação lipídica (TBARS), radical hidroxila e oxido nítrico, nas concentrações de 100, 300 e $900 \mu \mathrm{M}$. Todas as concentrações apresentaram atividade antioxidante. O potencial redutor, as reduções da produção de TBARS e inibição do radical DPPH• mostraram-se superiores ao controle positivo, o ácido ascórbico, evidenciando uma alta presença de substâncias antioxidantes. Estes resultados sugerem que esta espécie é promissora para a produção de fitoterápico onde a atividade antioxidante seja de ação desejada.

Palavras-chave: Lippia origanoides; Óleo essencial; Estresse oxidativo; Atividade antioxidante. 


\begin{abstract}
Oxidative stress is a constant threat to the body. As a result, a series of antioxidant defenses, in addition to cell repair systems, have evolved with the aim of protecting against destruction and damage caused by free radicals. Plants produce a huge variety of antioxidants that tend to act against cell damage by removing reactive oxygen species and reactive nitrogen species. Lippia origanoides Humboldt, Bonpland and Kunth, Verbenaceae family, is an aromatic shrub known as "Rosemary-do-campo", being responsible for several pharmacological and biological activities, including antioxidant protection. This work aimed to analyze the chemical composition of the essential oil of L.origanoides HBK (OELO) and evaluate its antioxidant activity in vitro. Therefore, the in vitro antioxidant potential was evaluated by the reducing potential, 2,2diphenyl-1-picrylhydrazyl (DPPH), lipid peroxidation inhibition (TBARS), hydroxyl radical and nitric oxide methods, at concentrations of 100, 300 and $900 \mu \mathrm{M}$. All concentrations showed antioxidant activity. The reducing potential, reductions in TBARS production and inhibition of the DPPH• radical were superior to the positive control, ascorbic acid, showing a high presence of antioxidant substances. These results suggest that this species is promising for the production of herbal medicine where the antioxidant activity is of desired action.
\end{abstract}

Keywords: Lippia origanoides; Essential oil; Oxidative stress; Antioxidant activity.

\title{
Resumen
}

El estrés oxidativo es una amenaza constante para el cuerpo. Como resultado, una serie de defensas antioxidantes, así como sistemas de reparación celular, han evolucionado con el objetivo de proteger contra la destrucción y el daño causado por los radicales libres. Las plantas producen una gran variedad de antioxidantes que tienden a contrarrestar el daño celular al eliminar las especies reactivas de oxígeno y las especies reactivas de nitrógeno. Lippia origanoides Humboldt, Bonpland y Kunth, familia Verbenaceae, es un arbusto aromático conocido como "Rosemary-do-campo", siendo responsable de varias actividades farmacológicas y biológicas, incluida la protección antioxidante. Este trabajo tuvo como objetivo analizar la composición química del aceite esencial de L.origanoides HBK (OELO) y evaluar su actividad antioxidante in vitro. Por lo tanto, el potencial antioxidante in vitro se evaluó mediante los métodos de potencial reductor 2,2-difenil-1-picrilhidrazilo (DPPH), inhibición de la peroxidación lipídica (TBARS), radical hidroxilo y óxido nítrico, a concentraciones de 100, 300 y $900 \mu \mathrm{M}$. Todas las concentraciones mostraron actividad antioxidante. El potencial reductor, las reducciones en la producción de TBARS y la inhibición del radical DPPH • fueron superiores al control positivo, ácido ascórbico, mostrando una alta presencia de sustancias antioxidantes. Estos resultados sugieren que esta especie es prometedora para la producción de medicamentos a base de hierbas donde se desea la actividad antioxidante.

Palabras clave: Origanoides de Lippia; Aceite esencial; Estrés oxidativo; Actividad antioxidante.

\section{Introdução}

A utilização de plantas com fins medicinais, para tratamento, cura e prevenção de doenças, é uma das mais antigas formas de prática medicinal da humanidade, sendo tão antiga quanto a espécie humana; e por muito tempo, produtos de origem mineral, vegetal e animal foram as principais fontes de fármacos (Siviero, Delunardo, Haverroth, Oliveira, \& Mendonça 2012). Os fitoterápicos e fitofármacos estão sendo o alvo das pesquisas no campo da farmacoterapia da depressão e de outros transtornos psiquiátricos, visto que um dos fatores motivadores desta preferência tem sido a preocupação com os efeitos adversos ocasionados pelas drogas sintéticas usadas atualmente no tratamento das patologias relacionadas ao sistema nervoso central (Faustino, Almeida, \& Andreatini, 2010).

Pesquisas científicas envolvendo a composição química, botânica e atividade farmacológica de plantas medicinais tornaram-se relevante na busca de novas drogas com propriedades terapêuticas. Um dos maiores e mais importantes fatores para esse interesse em novos compostos com propriedades farmacológicas é a enorme diversidade de constituintes químicos que podem ser selecionados, devido à complexidade da constituição química de plantas medicinais (Badke, Budó, Alvim, Zanetti, \& Heisler, 2012).

Dentre as plantas medicinais comumente utilizadas pela população, é objeto de estudo deste trabalho a espécie Lippia origanoides Humboldt, Bonpland e Kunth (HBK), família Verbenaceae, é um arbusto aromático que chega a atingir até 3 m de altura, nativa da América Central (México, Guatemala e Cuba), norte da América do Sul, especialmente na região amazônica (Guiana, Venezuela, Brasil e Colômbia) e Antilhas. Na Colômbia é conhecida como “Oregano del Monte”' (Orégano do 
Monte), no norte do Brasil, é conhecida como Salva-de-Marajó e Alecrim d'Angola. No Piauí é conhecida como "Alecrim-docampo", sendo amplamente dispersa na região (Santos et al., 2004; Stashenko et al., 2010).

Este trabalho teve como objetivo analisar a composição química do óleo essencial de L. origanoides HBK (OELO) e avaliar sua atividade antioxidante in vitro.

\section{Metodologia}

\section{Tipo de estudo}

Trata-se de um estudo experimental com abordagem quantitativa dos dados. Nos métodos quantitativos geram conjuntos ou massas de dados que podem ser analisados por meio de técnicas matemáticas, como percentual, estatísticas e probabilidades, métodos numéricos, métodos analíticos e a geração de equações e / ou fórmulas matemáticas aplicáveis a qualquer processo.

\section{Obtenção da solução do óleo essencial}

Foi utilizada biomassa aérea (folhas e ramos finos) da planta. A biomassa foi secada à temperatura ambiente. Cada amostra foi triturada e submetida a três horas de hidrodestilação tipo Clevenger. $\mathrm{O}$ óleo foi acondicionado em frasco de vidro âmbar e mantidos sob refrigeração à temperatura de aproximadamente $-4^{\circ} \mathrm{C}$.

\section{Caracterização do óleo essencial}

Os parâmetros de análise foram os seguintes: a temperatura do injetor foi fixada em $220^{\circ} \mathrm{C}$; a temperatura da interface foi programada para $240{ }^{\circ} \mathrm{C}$ e a coluna programada para operar a $60{ }^{\circ} \mathrm{C}$, com elevação de temperatura na taxa de $3{ }^{\circ} \mathrm{C}$ min -1 , até a temperatura de $240^{\circ} \mathrm{C}$. $\mathrm{O}$ gás de arraste empregado foi hélio, mantido num fluxo constante de $1,0 \mathrm{~mL}$ min-1. Após ajuste de todos os parâmetros do equipamento, injetou-se $1 \mu \mathrm{L}$ da fração volátil (DCM). A análise com o detector de massas foi realizada no modo 'scan', com o tempo de aquisição de 60,35 min; e corte do solvente em 2 min. A aquisição dos espectros de massas foi feita na faixa de 40 a 650 Daltons, pelo método da ionização por elétrons, com energia de ionização de $70 \mathrm{eV}$ (voltagem $1.5 \mathrm{kV}$, analisador do tipo quádruplo) e fonte de íons a $200{ }^{\circ} \mathrm{C}$.

\section{Preparação do óleo essencial}

As amostras do OE foram diluídas em solução salina 0,9\%, e Tween 80 0,05\% nas concentrações de 100, 300 e 900 $\mu \mathrm{M}$.

\section{Testes antioxidantes in vitro}

\section{Potencial redutor}

Alíquotas de $10 \mu \mathrm{L}$ de cada amostra foram tomadas e transferidas, para tubos de ensaio. Em seguida foi adicionado o tampão fosfato ( $500 \mu \mathrm{L} ; 0,2 \mathrm{M} ; \mathrm{pH}$ 6,6) e o ferricianeto de potássio $(500 \mu \mathrm{L}, 1 \%(\mathrm{p} / \mathrm{v})$. A mistura foi colocada em banho Maria a $50{ }^{\circ} \mathrm{C}$ por $20 \mathrm{~min}$. Depois dos $20 \mathrm{~min}$, foi adicionado ácido tricloroacético $(500 \mu \mathrm{L}, 10 \%)$, água destilada $(500 \mu \mathrm{L})$ e de cloreto férrico $(250 \mu \mathrm{L} ; 0,1 \%)$, com posterior agitação. A absorbância foi determinada no $\lambda=700 \mathrm{~nm}$, em triplicata utilizando a absorbância de $100 \%$ da atividade do padrão de ácido ascórbico nas concentrações referidas para as amostras. 


\section{Scavenging do radical DPPH}

Preparou-se o radical 2,2-difenil-1-picril-hidrazil (DPPH•) em etanol na concentração de $40 \mu \mathrm{g} / \mathrm{mL}$, em seguida a absorbância do radical DPPH• foi ajustada em 1.00 no Espectrofotômetro. Pipetou-se alíquotas da amostra e dos controles positivo e negativo. Foi adicionado $2.000 \mu \mathrm{L}$ do radical $\mathrm{DPPH} \bullet$ ajustado em 1.00 e agitou rapidamente à mão por 10 segundos. Deixo-o em repouso a temperatura ambiente por 30 minutos. Leu-se a absorbância em $515 \mathrm{~nm}$ da mistura reacional. Todo o procedimento foi realizado em baixa luminosidade. A seguinte fórmula é utilizada para calcular a capacidade antioxidante contra o radical DPPH:

$\%$ de inibição do radical DPPH• $=\{($ Abscontrole - Absmistura reacional $) \times 100\} /$ Acontrole

\section{Avaliação contra a peroxidação lipídica (inibição da formação de ácido tiobarbitúrico-TBARS)}

Adicionou-se homogenato de gema de ovo em $50 \mathrm{mM}$ de tampão fosfato (pH 7,4). Em seguida foram pipetadas as amostras em triplicata. Adicionou-se $0,5 \mathrm{~mL}$ de solução de dihidrocloridrato de 2,2'-azobis-2-metilpropinamida $0,12 \mathrm{M}$ $(\mathrm{AAPH})(120 \mathrm{mM})$. Realizou-se a reação durante 60 minutos $\left(37^{\circ} \mathrm{C}\right)$. Após resfriamento, foram adicionados $0,5 \mathrm{~mL}$ de ácido tricloroacético $(15 \%)$ e $0,5 \mathrm{~mL}$ de ácido tiobarbitúrico $(0,6 \%)$ e realizou-se a reação por 20 minutos $\left(97^{\circ} \mathrm{C}\right)$. Centrifugou-se a amostra e fez-se a leitura do sobrenadante usando um espectrofotômetro a $532 \mathrm{~nm}$.

\section{Scavenging de Radical Hidroxila}

Pipetou-se o volume da amostra e os controles, em seguida adicionou-se meio reacional: $150 \mu \mathrm{L}$ de EDTA 1,5 mM+ $150 \mu \mathrm{L}$ de frutose $50 \mathrm{mM}+150 \mu \mathrm{L}$ de cloreto férrico $5 \mathrm{mM}+150 \mu \mathrm{L}$ de $\mathrm{H} 2 \mathrm{O} 2100 \mathrm{Mm}$. Levou-se a mistura ao banho-maria à temperatura de $50 \mathrm{oC}$ durante $30 \mathrm{~min}$, posteriormente deixou esfriar e acrescentou-se $500 \mu \mathrm{l}$ de ácido fosfórico $4 \%$ e $500 \mu 1$ de ácido tiobarbitúrico (TBA) $1 \%$. Novamente a mistura foi levada ao banho-maria à temperatura de $100 \mathrm{oC}$ durante 15 min. Leuse em espectrofotômetro a $532 \mathrm{~nm}$.

\section{Produção de nitrito in vitro}

Pipetou-se o volume da amostra e os controles (positivo e negativo). Em seguida adicionou-se o meio reacional: $1 \mathrm{ml}$ de Nitroprussiato de sódio em Tampão Fosfato $20 \mathrm{mM}$ (pH 7,4). Colocou-as em Banho Maria a $37^{\circ} \mathrm{C}$ durante $1 \mathrm{~h}$. Acrescentou-se $500 \mu 1$ do Reagente de Griess em cada um dos tubos. Após 10 minutos leu-se em espectrofotômetro a $540 \mathrm{~nm}$.

\section{Análise Estatística}

Os dados obtidos foram obtidos como a média \pm erro padrão da média (E.P.M.), sendo avaliados por meio da Análise de Variância (ANOVA) seguidos pelo teste de $t$-Student-Newman-Keuls como post hoc. A estatística foi realizada por meio do GraphPad Prism versão 5,01 software (1992-2007, GraphPadSoftware Inc).

\section{Resultados e Discussão}

\section{Caracterização do óleo essencial}

A análise das frações voláteis por cromatografia gasosa acoplada à espectrometria de massas (CG-EM) forneceu como resultado os cromatogramas. Os espectros de massas concernentes a cada pico apresentaram similaridade significativa com a biblioteca do software adotado, biblioteca Willey229®. Os índices de retenção de cada constituinte foram calculados, com relação a um padrão de hidrocarbonetos de cadeia linear, alifática (C9 - C20) e não ramificada; e utilizados, além dos espectros de massas, como fator de identificação. A Tabela 1 contém a relação dos constituintes voláteis identificados. 
Entre os constituintes identificados destacaram-se p-cimeno (23,89\%), timol (21,78\%) e carvacrol (18,87\%). O timol e carvacrol são fenóis monoterpenóides biossintetizados em plantas a partir do $\gamma$-terpineno e p-cimeno. Por isso, estes últimos estão sempre presentes em óleos essenciais que contém timol e carvacrol. Além disso, intermediários biossintéticos também podem estar presentes, como: terpinen-4-ol, álcool cumino e p-cimen-8-ol (Baser \& Demirci, 2007), como pode ser observado na Tabela 1. Tais resultados corroboram com aqueles encontrados por Santos et al. (2004), que analisando três coleções de L. origanoides Kunth, encontraram como compostos majoritários o carvacrol (33,5-42,9\%), p-cimeno (11,9-15,8\%), $\gamma$-terpineno $(8,0-10,5 \%)$ e timol $(5,1-8,4 \%)$.

\section{Testes antioxidantes in vitro}

O princípio da atividade antioxidante baseia-se na disponibilidade de elétrons para neutralizar quaisquer radicais livres. De acordo com Gülçin, Elmastas e Aboul-Enein (2012), atualmente existe um crescente interesse em substâncias que apresentem propriedades antioxidantes, que são úteis para a saúde humana, tanto como componentes dos alimentos, quanto como substâncias preventivas que podem ser específicas de produtos farmacêuticos.

Segundo Ruberto e Baratta (2000) os fenóis são antioxidantes eficientes, assim as moléculas como timol e carvacrol, são responsáveis pela atividade antioxidante de muitos óleos essenciais que os contêm. A presença nessas moléculas de grupos metileno fortemente ativados, de acordo com os autores, é provavelmente a razão para este comportamento.

\section{Potencial redutor}

Os redutores presentes na amostra são oxidados, enquanto que os íons férricos são reduzidos para íons ferrosos, como mostrado abaixo.

Ferricianeto de potássio + Cloreto férrico $\stackrel{\text { Antioxidante }}{\longrightarrow}$ Ferricianeto de potássio+ Cloreto ferroso (Singhal, Paul, \& Singh, 2013)

A concentração de $100 \mu \mathrm{M}$ do OELO aumentou em 183,3\% a redução de Fe3+ para Fe2+ em comparação com o controle. A concentração de $300 \mu \mathrm{M}$ aumentou em 276,7\% e de $900 \mu \mathrm{M}, 351,7 \%$. A concentração de $100 \mu \mathrm{M}$ Ácido Ascórbico (AA) aumentou em 252,5\% a redução de Fe3+ para Fe2+ em comparação com o controle. A $300 \mu \mathrm{M}$ aumentou em 293,3 \% enquanto que a concentração de $900 \mu \mathrm{M}$ aumentou em 329,2 \%. Como mostra a Figura 1. De acordo com esses resultados, a CE50 do OELO necessária para reduzir ferricianeto de potássio $(\mathrm{Fe} 3+)$ à ferrocianeto de potássio $(\mathrm{Fe} 2+)$ em $50 \%$ da sua absorbância inicial foi de $118,7 \mu \mathrm{M}$, entretanto o AA apresentou CE50 de 30,54 $\mu \mathrm{M}$.

Figura 1. Teste do potencial redutor $(\mathrm{Fe} 3+/ \mathrm{Fe} 2+)$ do OELO.

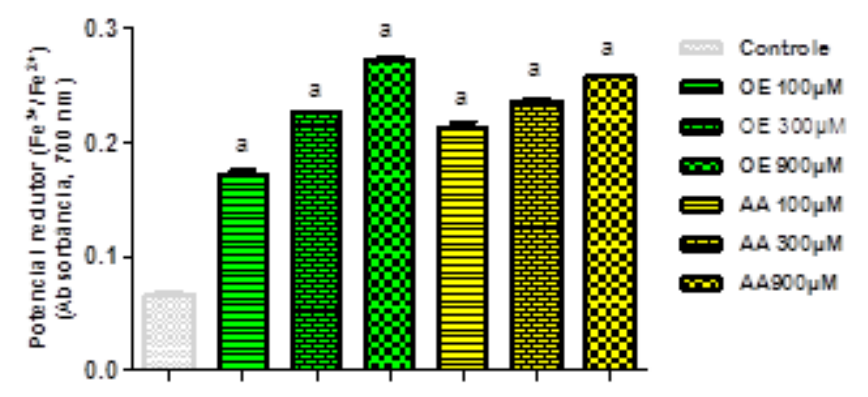

Legenda: Efeitos do óleo essencial de Líppia origanoides na redução do íon Fe3+ para Fe2+. Os valores representam a média \pm E.P.M. dos valores de inibição in vitro, $n=3$, experimentos em triplicata. $\mathrm{O}$ ácido ascórbico usado como padrão antioxidante.a $\mathrm{p}<0,001$ versus controle em relação ao sistema (meio reacional) (ANOVA e t-Student-Neuman-Keuls como post hoc teste). Fonte: Dados da pesquisa. 


\section{DPPH}

Neste ensaio, o antioxidante reage com o radical DPPH•, convertendo-o em sua forma reduzida. Nesta reação, a solução metanólica de DPPH•, inicialmente de coloração violeta, torna-se descolorida e o grau desta descoloração indica a habilidade do antioxidante em sequestrar o radical livre (Molyneux, 2004).

Segundo Moon e Shibamoto (2009), o teste DPPH• é simples, sensível e mede a capacidade de uma substância potencialmente antioxidante de sequestrar o radical livre DPPH•, que em solução etanólica apresenta coloração violeta. A atividade antioxidante é avaliada pelo monitoramento do decréscimo da absorbância, sendo esta proporcional à concentração de substâncias antioxidantes presentes na amostra testada (Lim, Y.Y., Lim, T.T., \& Tee, 2007; Goulart, Oliveira, \&Valentim, 2009).

O resultado antioxidante correspondente ao sequestro do radical DPPH pelo OELO em diferentes concentrações está representado na figura 5. Os valores da capacidade antioxidante do OELO frente ao radical DPPH• nas concentrações de 100, 300 e $900 \mu \mathrm{M}$ foram respectivamente de 13,49\%, 29,84\% e 34,12\%, na qual reduziu de forma significativa (p<0,001) a concentração da solução de radical DPPH• (sistema). Nas mesmas condições experimentais o Ácido Ascórbico (AA) apresentou capacidade antioxidante de $9,06 \%, 9,47 \%$ e $27,51 \%$, respectivamente.

De acordo com os resultados contra o radical DPPH•, a CE50 do OELO de 125,4 $\mu \mathrm{M}$, se apresentando menor que a CE50 do AA com 315,3 $\mu \mathrm{M}$.

Figura 2. Efeitos do OELO na remoção de DPPH.

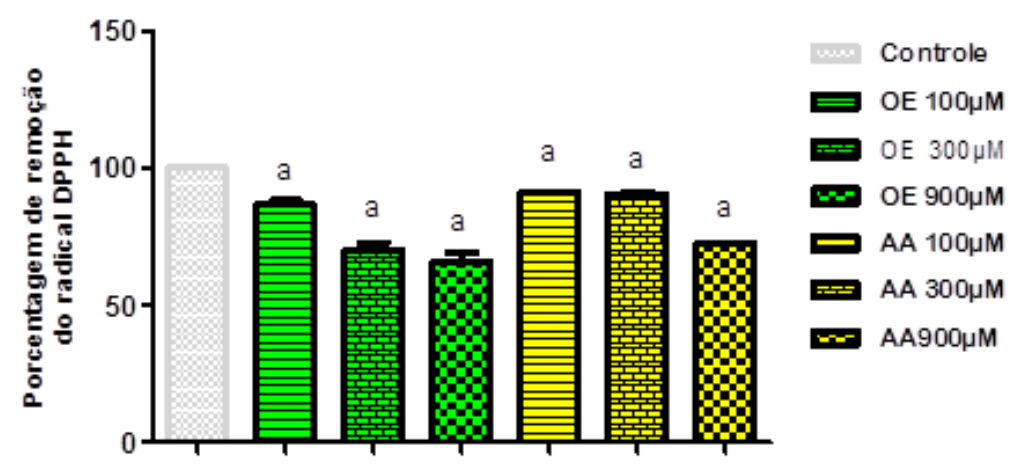

Legenda: Efeitos do óleo essencial de Líppia origanoides na remoção do radical DPPH Os valores representam a média \pm E.P.M. dos valores de inibição in vitro, $n=3$, experimentos em triplicata. $O$ ácido ascórbico foi usado como padrão antioxidante.a p $<0,001$ versus controle em relação ao sistema (meio reacional) (ANOVA e Neuman-Keuls como post hoc teste).

Fonte: Dados da pesquisa.

\section{Avaliação contra a peroxidação lipídica (inibição da formação de ácido tiobarbitúrico-TBARS)}

A atividade antioxidante, analisada pelo método TBARS quantificou a peroxidação lipídica e consequente dano na membrana celular, medindo assim o estresse oxidativo. O AAPH, um composto azo hidrossolúvel, é utilizado como gerador de radicais livres. A sua decomposição produz nitrogênio molecular, e radicais carbonilas, os quais, por sua vez, reagem com o ácido tiobarbitúrico, resultando na formação de TBARS (Zin, Abdul-Hamid, \& Osman 2002; Fitó, Torre, \& Covas 2007; Moon \& Shibamoto, 2009).

$\mathrm{O} \mathrm{OE}$, em todas as concentrações testadas, foi capaz de prevenir a peroxidação lipídica, reduzindo a quantidade de TBARS formado. Resultado semelhante foi obtido com o ácido ascórbico (AA), que também inibiu a produção a de TBARS. As concentrações utilizadas de OE 100, 300 e $900 \mu \mathrm{M}$ reduziram a produção de TBARS em 5,21\%, 30,46\% e 81,20\% respectivamente. Comparativamente ao controle positivo utilizado, o AA nas mesmas concentrações 100 , 300 e $900 \mu \mathrm{M}$, promoveu inibição de $13,67 \%, 28,29 \%$ e 39,87\% na produção de TBARS. Pode-se perceber que na concentração $900 \mu$ M a 
redução produzida pelo OE foi muito superior ao do controle, como pode ser visto na figura 3. De acordo com os resultados da capacidade antioxidante pela inibição da peroxidação lipídica, o valor da CE50 foi de 340,2 $\mu \mathrm{M}$ e 155,8 $\mu \mathrm{M}$ para OELO e AA, respectivamente.

Figura 3. Efeitos do OELO contra a produção de substâncias reativas com o ácido tiobarbitúrico.

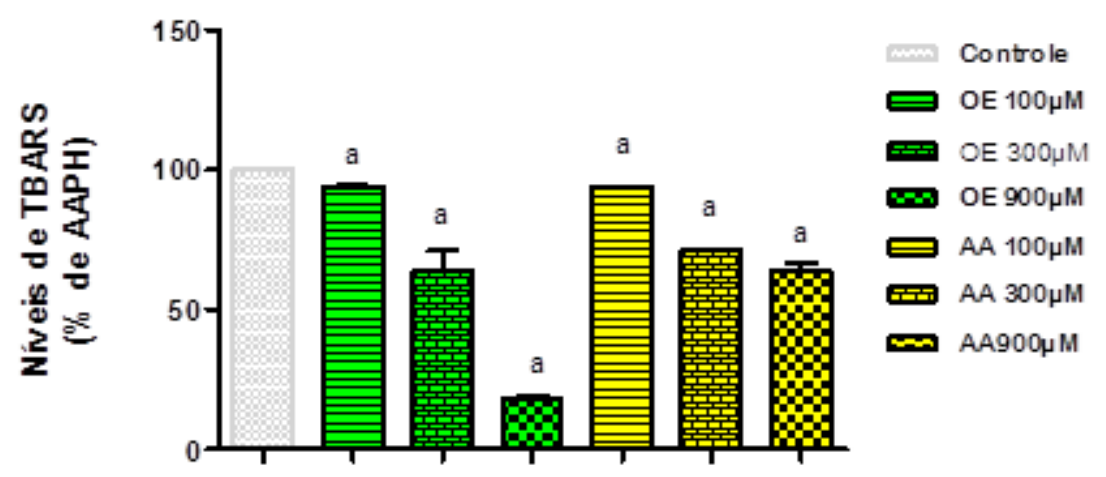

Legenda: Efeitos do óleo essencial de L.origanoides HBK contra a produção de substâncias reativas com o ácido tiobarbitúrico. Ácido ascórbico 100,300,900 $\mu \mathrm{M}$ foi usado como padrão antioxidante. Os valores representam a média \pm E.P.M. dos valores de inibição in vitro, $\mathrm{n}$ $=3$, experimentos em triplicata. ap $<0,05$ versus AAPH em relação ao sistema (meio reacional) (ANOVA e t-Student-Neuman-Keuls como post hoc teste)

Fonte: Dados da pesquisa.

\section{Scavenging de Radical Hidroxila}

O radical hidroxila $(\bullet \mathrm{OH})$ avalia a atividade antioxidante de uma substância baseado na capacidade removedora de radicais livres formados em espécies menos reativas. Neste método o $\bullet \mathrm{OH}$ é gerado pela reação de Fenton. Na presença do • $\mathrm{OH}$, a 2-desoxirribose é degradada à malonaldeído, sendo então quantificado, cujo processo reacional está descrito abaixo (Huang, \& Prior 2005; Payá, Halliwell, \& Hoult, 1992).

I. Reação de Fenton:

$\mathrm{O}_{2-}+\mathrm{Fe}^{+3} \rightarrow \mathrm{O}_{2}+\mathrm{Fe}^{+2}$

$\mathrm{H}_{2} \mathrm{O}_{2}+\mathrm{Fe}^{+2} \rightarrow \mathrm{OH}^{-}+\mathrm{HO} \cdot+\mathrm{Fe}^{+3}$

II. Reação de degradação da 2-desoxirribose produzindo malonaldeído (MAD):

2-desoxirribose $+\cdot \mathrm{OH} \longrightarrow \mathrm{MAD}$

III. Por último, o MAD reage com como com o ácido tiobarbitúrico, formando também TBARS.

O estudo demonstrou que $\mathrm{OE} 100,300$ e $900 \mu \mathrm{M}$ produziu a remoção do $\cdot \mathrm{OH} 21,4 \%, 59,5 \%$ e $62,06 \%$, respectivamente. O AA (padrão) também reduziu significativamente a quantidade deste radical, 29,4\%, 59,5\% e 66,4\% em 100, 300 e $900 \mu \mathrm{M}$, respectivamente. Pode-se perceber que a inibição do radical foi semelhante entre o OE e O AA, como mostrado na Figura 4.

Diante dos resultados obtidos na inibição da degradação da 2-deoxirribose, o valor da CE50 foi de 133,3 $\mu \mathrm{M}$ e 125,1 $\mu \mathrm{M}$ para OELO e AA, respectivamente. 
Figura 4. Efeitos do OELO na remoção do radical hidroxila.

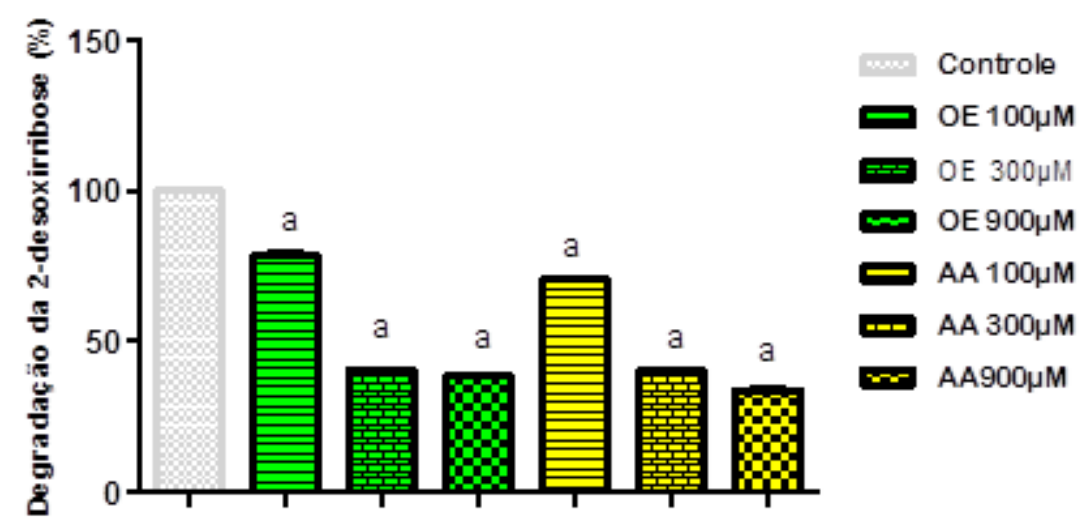

Legenda: Efeitos do óleo essencial de L.origanoides HBK na remoção de radical hidroxila. Ácido ascórbico 0,45nM foi usado como padrão antioxidante. Os valores representam a média \pm E.P.M. dos valores de inibição in vitro, $\mathrm{n}=3$, experimentos em triplicata. ap $<0,001$ versus AAPH em relação ao sistema (meio reacional) (ANOVA e t-Student-Neuman-Keuls como post hoc teste).

Fonte: Dados da pesquisa.

\section{Produção de nitrito in vitro}

O método de remoção do metabólito nitrito para avaliação da atividade antioxidante também foi utilizado, baseado na produção de $\mathrm{NO}$ • a partir da decomposição de nitroprussiato de sódio em solução aquosa, como mostra a reação:

Adaptado de Ramos, Cavalheiro e Cavalheiro (2006).

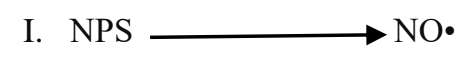

Por sua vez, este radical reage com o oxigênio gerando o radical nitrito

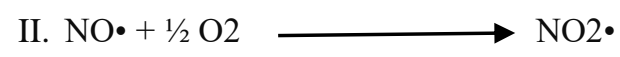

O radical nitrito reage com o radical óxido de nítrico e forma-se o anidrido nitroso, um reagente nitrosante (Sykes, 1991):

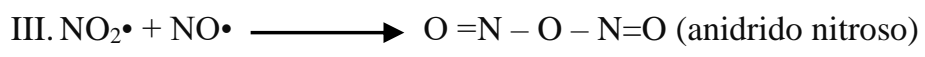

O anidrido nitroso, ao reagir com a sulfanilamida do reagente de Griess (1\% de sulfanilamida em 5\% de ácido fosfórico e dicloridrato de $\mathrm{N}$-(1 -naftil)-etilenodiamina) a 1\% em água, forma o sal de diazônio, que em seguida, realiza acoplamento diazo com o N-(1 -naftil)-etilenodiamina para produzir o diazo composto de cor violeta, um cromóforo de absorção máxima em $546 \mathrm{~nm}$. Se no meio reacional houver substâncias antioxidantes, estas vão competir com o oxigênio, e a produção do radical nitrito NO2• será reduzida. As reações a seguir mostram a produção do cromóforo: 
Figura 5. Efeitos do OELO na produção de nitrito.

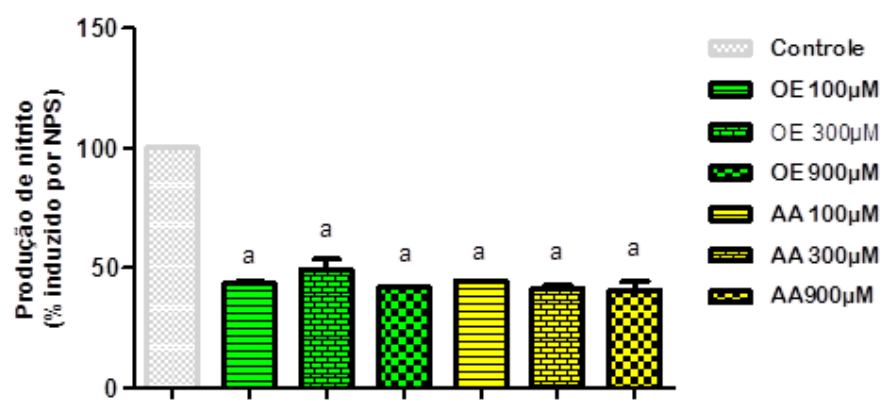

Legenda: Efeitos do OE na remoção do metabólito nitrito. Os valores representam a média \pm E.P.M. dos valores de inibição in vitro, $\mathrm{n}=3$, experimentos em duplicata. O AA foi usado como padrão antioxidante. ap $<0,001$ versus controle em relação ao sistema (meio reacional) (ANOVA e t-Student-Neuman-Keuls como post hoc teste); ap<0,001 versus sistema em relação ao controle (ANOVA e t-Student-NeumanKeuls como post hoc teste).

Fonte: Dados da pesquisa.

OELO reduziu a produção de nitrito em 56,14\%, 50,80\% e 58,05\% (100, 300 e $900 \mu \mathrm{M}$, respectivamente) enquanto o AA reduziu em 55,6 \%, 58,4\% e 59,51\% (100, 300 e $900 \mu \mathrm{M}$, respectivamente). De acordo com os resultados da inibição do oxido nítrico, a CE50 do OELO foi de $1030 \mu \mathrm{M}$, e do AA de $1643 \mu \mathrm{M}$.

\section{Conclusão}

O OE exerce efeito antioxidante in vitro mediante os métodos utilizados. Este estudo fornece subsídios para a exploração de efeito farmacológico da L.origanoides HBK, uma vez que a terapêutica farmacológica atual para o tratamento de doenças como Alzheimer, Parkinson, esclerose múltipla, doença de Huntington, epilepsia e alguns tipos de neoplasias pode ser relacionado aos mecanismos antioxidantes. Além disso, compostos com ação antioxidante podem retardar o envelhecimento. Dessa forma, a busca por novos agentes antioxidantes é extremamente necessária e atualmente é objeto de interesse em novas pesquisas pela indústria farmacêutica.

\section{Referências}

Badke, M. R., Budó, M. L. D., Alvim, N. A. T., Zanetti, G. D., \& Heisler, E. V. (2012). Popular knowledge and practices regarding healthcare using medicinal plants. Tex Cont Nursing, 21(2), 363-370.

Baser, K. H. C., \& Demirci, F. (2007). Chemistry of Essential Oils. In: R. G. Berger (Coord.). Flavours and Fragrances: Chemistry, Bioprospecting and Sustainability (pp. 43-86). Heidelberg: Springer.

Faustino, T. T., Almeida, R. B., \& Andreatini, R. (2010). Plantas medicinais no tratamento do transtorno de ansiedade generalizada: uma revisão dos estudos clínicos controlados. Revista Brasileira de Psiquiatria, 32(4), 429-436.

Fitó, M., Torre, R., \& Covas, M. I. (2007). Olive oil and oxidative stress. Molecular Nutrition \& Food Research, $51(10), 1215-1224$.

Goulart, M. O. F., Oliveira, A. C., \& Valentim, I. A. (2009). Fontes vegetais naturais de antioxidantes. Química Nova, 32(3), 689-702.

Gülçin, I., Elmastas, M., \& Aboul-Enein, H.Y. (2007). Determination of antioxidant and radical scavenging activity of basil (Ocimum basilicum L. family Lamiaceae) assayed by different methodologies. Phytotherapy Research, 21(4), 354-61.

Huang, D., Ou, B., \& Prior, R. L. (2005). The chemistry behind antioxidant capacity assays. Journal of agricultural and food chemistry, 53(6), 1841 -1856.

Lim, Y. Y., Lim, T. T., \& Tee, J. J. (2007). Antioxidant properties of several tropical fruits: a comparative study. Food Chemistry, $103(2)$, 1003 -1008.

Molyneux, P. (2004). The use of the stable free radical diphenylpicrylhydrazyl (DPPH) for estimating antioxidant activity. Songklanakarin Journal of Science and Technology, 26(2)211-9.

Moon, J., Shibamoto, T. (2009). Antioxidant Assays for Plant and Food Components. Journal of Agricultural and Food Chemistry. 57(5), $1655-1666$.

Payá, M.; Halliwell, B.; Hoult, J. R. S. (1992). Interactions of a series of coumarins with reactive oxygen species: scavenging of superoxide, hypochlorous acid and hydroxyl radicals. Biochemical pharmacology, 44(2), 205-214. 
Research, Society and Development, v. 10, n. 8, e2810816716, 2021

(CC BY 4.0) | ISSN 2525-3409 | DOI: http://dx.doi.org/10.33448/rsd-v10i8.16716

Ramos, L. A., Cavalheiro, C. C. S., Cavalheiro, E. T. G. (2006). Determinação de nitrito em águas utilizando extrato de flores. Química Nova, $29(5), 1114$.

Ruberto, G., \& Baratta, M. (2000). Antioxidant activity of selected essential oil components in two lipid model systems. Food Chemistry, 69, 167-174.

Santos, F. J. B., Lopes, J. A. D., Citó, A. M. G. L., Oliveira, E. H., Lima, S. G., \& Reis, F. A. M. (2004). Composition and biological activity of essential oils from Lippia origanoides H.B.K. The Journal of Essential Oil Research, 16, 504-506.

Singhal, M., Paul, A., \& Singh, H. P. (2013). Synthesis and reducing power assay of methyl semicarbazone derivatives. Journal of Saudi Chemical Society, 18, $121-127$.

Siviero, A., Delunardo, T. A., Haverroth, M., Oliveira, L. C., \& Mendonça, A. M. S. (2012). Plantas medicinais em quintais urbanos de Rio Branco, Acre. Revista Brasileira de Plantas Medicinais, 14(4), 598-610.

Sykes, P. (1991). A Guidebook to mechanism in organic chemistry, (6a ed.), Longman Scientific \& Technical.

Stashenko, E. E., Martínez, J. R., Ruíz, C. A., Arias, G., Durán. C., Salgar, W., \& Cala, M. (2010). Lippia origanoides chemotype differentiation based on essential oil GC-MS and principal component analysis. Journal of separation Science, 33,93-103.

Zin, Z. M., Abdul-Hamid, A., \& Osman, A. (2002). Antioxidative activity of extracts from Mengkudu (Morindacitrifolia L.) root, fruit and leaf. Food Chemistry, 78, 227-231. 